\title{
Double Chamber of Right Ventricle (DCRV) - A Case Report
}

\author{
AMA Rahim ${ }^{1}$, KA Hasan $^{1}$, MK Hasan ${ }^{1}$, MMAA Mamun ${ }^{1}$, ABMA Salam ${ }^{2}$, MA Arif $^{1}$, KN Mahmood $^{1}$
}

${ }^{1}$ Department of Cardiac Surgery, NICVD, ${ }^{2}$ Department of Paediatric, Cardiology, NICVD, Dhaka

\author{
Keywords: \\ Double chamber \\ of Right \\ ventricle, \\ intracardiac \\ repair.
}

\begin{abstract}
:
Primarily double chamber of Right ventricle (DCRV) is an uncommon congenital anomaly consists of one or more anomalous muscle bundles(AMB) that divide Right ventricle into proximal high and distal low pressure chamber. Outcome of surgical treatment is excellent if diagnosed properly. A 5years old girl presented with breathlessness on exertion and repeated attack of cough, fever for last 4 years .patient ultimately diagnosed as DCRVand underwent intracardiac repair by open heart surgery. Her postoperative outcome was uneventful. Patient is discharged on $8^{\text {th }}$ postoperative day after follow up postoperative chest X Ray and Echocardiography .
\end{abstract}

(Cardiovasc. j. 2011; 3(2): 226-229)

\section{Introduction :}

DCRV better understood as a form of septated right ventricle caused by the presence of abnormally located or hypertrophied muscle bands that devide right ventricle into high pressure proxiumal and low pressure distal chamber.these muscle bundles ran between an area located in ventricular septum beneath the level of septal leaflet of tricuspid valve and the anterior wall of right ventricle.progressive obstraction can lead to right ventricular outflow tract obstraction even right heart failure.DCRV was originally described 130 years ago,but clinical seris begins describing it extensively in $1960 .^{1}$

DCRV is a rare congenital anomaly representing $0.5-2 \%$ of total congenital heart disease and 10\% of total VSD patient. Frequently associated lesion include perimembranous VSD, pulmonary valve stenosis, descrete subaortic stenosis .Various other association include DORV (double outlet of right ventricle), tetralogy of fallot (TOF), total anomalous pulmonary venous connection (TAPVC), complicated/uncomplicated transposition of great arteries(TGA), pulmonary atresia with intact ventricular septum and ebstein anomaly.DCRV has also been reported in down syndrome and noonan syndrome. ${ }^{2}$ DCRV can present at any age DCRV can present at any age preferably below 20 years. Newborn,foetal \& adult patients may present with
DCRV. Mean age is 3-52years, male female ratio $2: 1$. Origin of anomalous muscle bundles(AMB) is debated, embryologically failure to incorporate bulbous cordis into right ventricle or an elevated hypertrophied moderator band. ${ }^{1}$

\section{Case Report:}

A 05 yrs aged girl of $15 \mathrm{~kg}$ presented with the complaints of repeated cough and fever and shortness of breath on exertion for 4 years.Patient's mother states that she suffered recurrent fever with at 01 to 02 months interval since her one year of age. Fever was not associated with chill \& rigor, chest pain, joint pain or swelling. Patient developed shortness of breath on exertion (NYHA-II) from one year of age. No $\mathrm{H} \backslash \mathrm{O}$ diurnal, seasonal or postural variation of $\mathrm{SOB}$ (shortness of breath ).

General exam revealed, patient is not anaemic, ichteric or cynanotic. Oedema \& clubbing was absent. Cardiovascular system examination revealed- Pulse: 100 / min, regular, normal in volume \& character. There was no radio-radial or radio-femoral delay. All the peripheral pulses are symmetrically present. JVPwas normal. BP: 100 / $60 \mathrm{~mm}$ of Hg. Apex beat was in Lt. $5^{\text {th }}$. ICS lateral to mid clavicular line. A systolic thrill was present over Lt. $2^{\text {nd }} \& 3^{\text {rd }}$ ICS. Lt.parasternal heave was

Address of Correspondence: Dr A .M. Asif Rahim, Department of Cardiac surgery, NICVD,Dhaka .Bangladesh e-mail:titormc@yahoo.com 


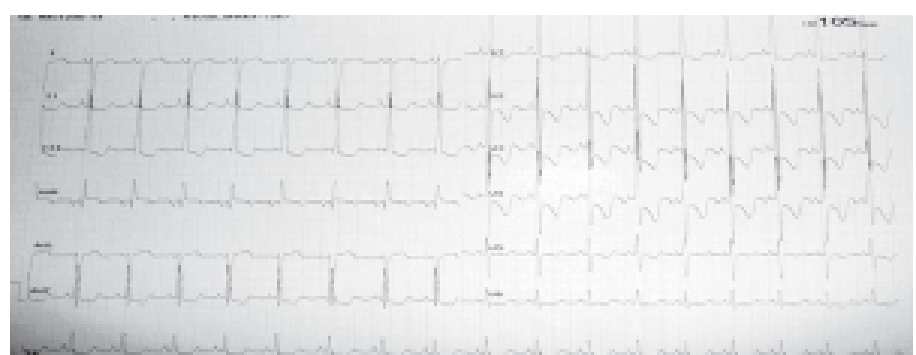

Fig.-1: ECG showed Right Ventricular Hypertrophy

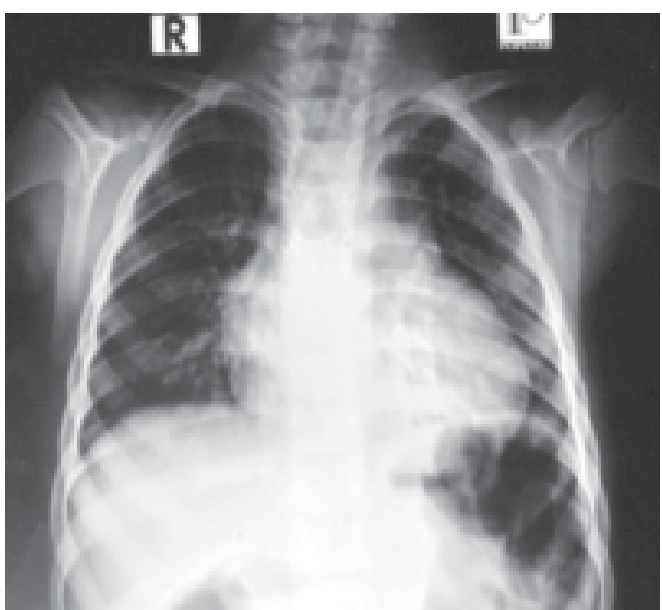

Fig.-2: Chest X-Ray showed cardiomegaly
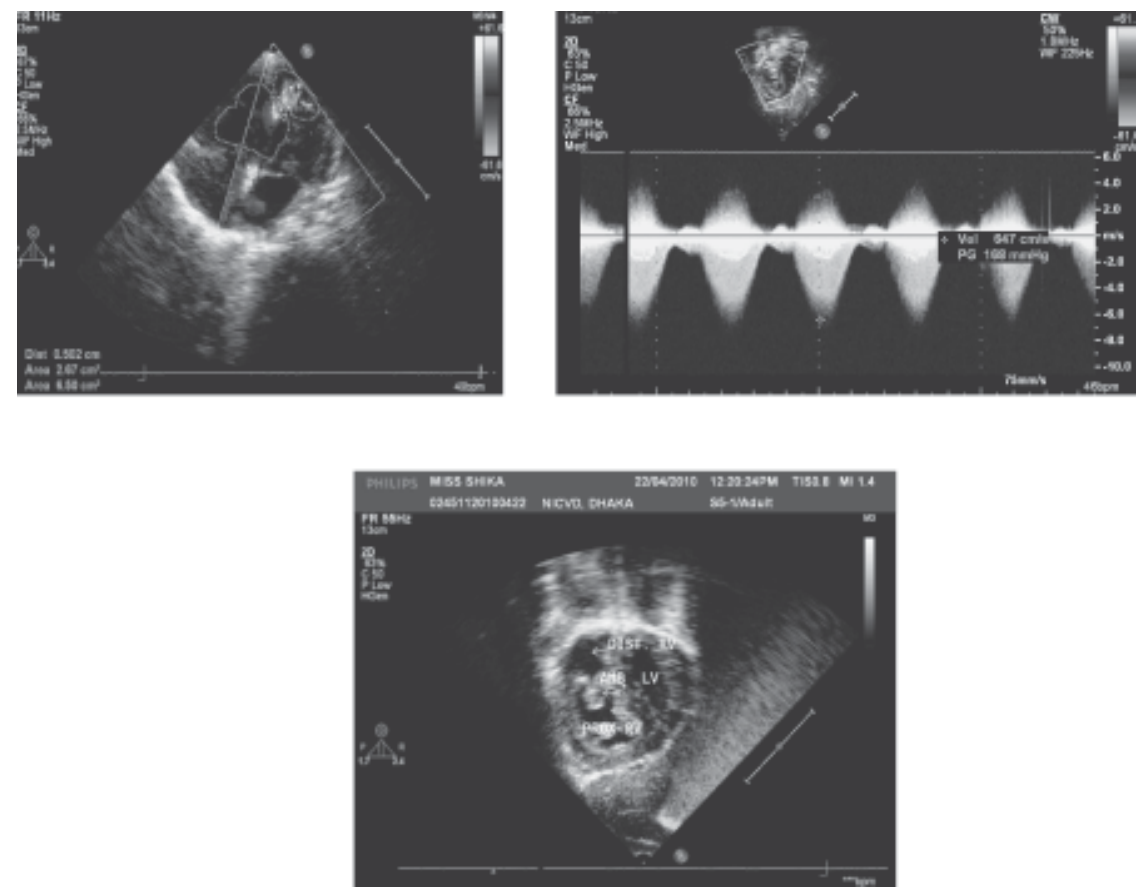

Fig.-3: Echocardiographic features of Double Chamber Right Ventricle

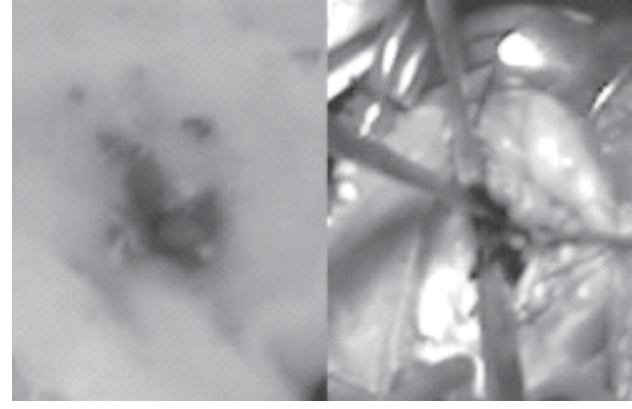

Fig.-4: Peroperative DCRV and resected hypertrophied muscle bundles in a gauge

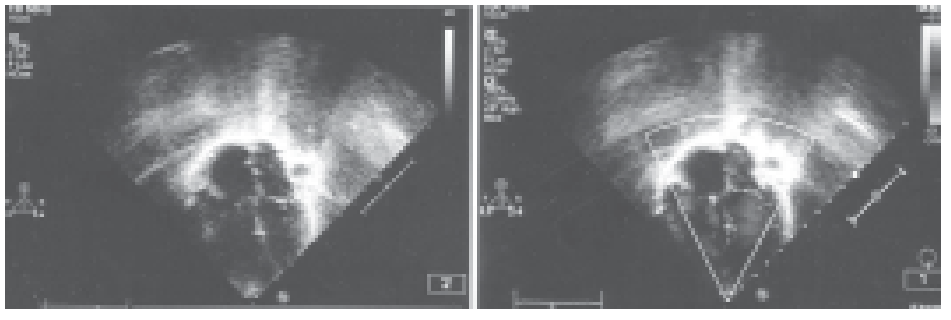

Fig.-5: Postoperative echocardiography showing pressure in right ventricle is with in normal limit 
present. S1 \& S2 were audible and normal.Ejection Systolic murmur of grade 5 / 6 was present over Lt. $2^{\text {nd }} \& 3^{\text {rd }}$ ICS with radiation to infraclavicular region. Other systemic examination revealed no abnormality.

$\mathrm{X}$-Ray chest P/A view revealed cardiomegaly. ECG showed feature of right ventricular hypertrophy. Echocardiography revealed Double Chamber RV due to thick septomarginal band and thick trabecular band causing severe mid cavity or proximal RVOT obstruction with PPG $122 \mathrm{~mm}$ of Hg. PV, PA : normal. IVS : intact. There was a PFO with occasional $R-L$ shunt. Cardiac catheterization revealed double Chamber RV (DCRV) due to anomalous muscle band from the septomarginal band and from the trabecular portion $\mathrm{RV}$, dividing into proximal $\mathrm{RV}$ and distal RV. Proximal RV pressure is very high $(95 / 25 / 53)$ then distal RV pressure (12/04/10). Pressure gradient is $83 \mathrm{~mm}$ of Hg.Pulmonary artery was normal. So patient was finally diagnosed as DCRV(confirmed diagnosis)

Surgical technique:Intracardiac repair done by following method-after establishment of all invasive \& noninvasive line median sternotomy was done under G/A. Thymus dissected. Pericardiotomy done. Pericardial sling applied. Aortic, venous \& aortic root cannulation was done after pursestrings suture, snareing \& inj. Heparin. CardioPulmonaryBypass established. Cross clamp applied. Cold blood antigrade cardioplagia given \& heart was made arrested. RA tomy was done. PFO was seen. TV was retracted by two VSD retractor. Detailed anatomy was evaluated. There is no VSD. Huge hypertrophied muscle band was present which divided RV into proximal \& distal part. PV orifice could not visualized. A Vent was passed through PFO to LA.Hypertrophied huge muscle band of RV were resected adequately and carefully. Pulmonary valve orifice was visualized. Serial Heggeres dilators were passed through PV orifice. Haggeres dilator no- 4 was passed with difficulties (13 mm).Revision resection of Hypertrophied muscle bands of RV were done meticulously. PV leaflet was stressed and Heggeres dilator no-5 was passed easily $(16 \mathrm{~mm})$. PFO was directly closed. $\mathrm{RV}$ pressure in proximal part was recorded, it was 39 / 11 (19). Pre operative pressure $95 / 25$ (53) was recorded in CATH. Postoperative period was uneventful.

\section{Discussion:}

First successful surgical repair of DCRV was reported at 1962 through right ventriculectomy. Now a days it can be done by right atriotomy; combined pulmonary arteriotomy and right atriotomy approach.Typically DCRV diagnosed during childhood and adolescent are most common. 2D echocardiography,cardiac catheterisation, and cineangiography are the key in diagnosis of DCRV. Surgical correction consists of resection of anomalous muscle bundles and correction of associated anomalies through right ventriculectomy. ${ }^{1}$

Most patient are asymptomatic. Detection of holosystolic murmur is the common reason for referral. But VSD with significant pulmonary outflow tract obstraction present with cyanosis, fatigue or exercise intollerance. RV heave, hepatomegaly,tachypnoea are features of right ventricular hypertension leading to right ventricular failure,cyanosis, fatigue and failure to thrive etc. ${ }^{2}$

The main preoperative findings are $-{ }^{2}$

1) Documentation by cardiac cath of systolic pressure gradient of RV inflow and outflow tract more than $40 \mathrm{~mm} \mathrm{Hg}$ at rest.

2) RV angiogram high and low obstraction by AMB below infundibulum.

3) Absent infundibular hypoplasia.

4) Direct observation of intracardiac muscle bundle during surgical repair.

5) Proximal chamber RV pressure- 89.9+-35.1(44$190 \mathrm{~mm}$ of $\mathrm{Hg}$ ), RV pressue $>\mathrm{LV}$ pressure (42.4\%) and systolic pressure gradient in two chamber is 6.5+-38.5 (20-170 $\mathrm{mm}$ of $\mathrm{Hg})$.

After surgical correction RV outflow tract gradient 14.5+-9.3 (2-30 $\mathrm{mm}$ of $\mathrm{Hg})$ and a mid RVOT gradient $30 \mathrm{~mm}$ of $\mathrm{Hg}$ with nonsignificant residual VSd is 
observed in recent study. Post surgical follow up done 16.5+-8.9(2.5-31years). ${ }^{3}$ Failure to diagnose DCRV led to either closure of one of the portion of right ventricle with fatal outcome or reoperation in VSD cases although obstracted RV remained.residual mean RVOT obstraction nonheamodynamically significant residualVSD , TR,AR are usual postoperatively. A few years ago death rate after surgical repair of DCRV was $1.7 \%$ . But recent study revealed no major symptoms and no early or late hospital death no patient require any further operation to relieve subsequent RVOT obstruction. ${ }^{1}$

\section{Conclusion:}

Surgical repair of DCRV yields excellent heamodynamic and functional result over short and long term.

\section{Refferences:}

1) Xue-jun Mao, Jing-fung Zhang, Ruo-bin Wu. JingJangHe,Wei-daChen,Xiao-Hui Yang. The diagnosis and surgical treatment of DCRV. Asia Pacif Journ.of Thorac and Cardiovas Surg 1996;5(1) : 14-17.

2) Yashikazu Hachiro,Nobuyaiki, Takag.Tatsuya koyanag,Masayuki Marikawa,Tomio Abe. Repair of DCRV surgical result and longterm follow up. Ann Thorac Surg 2001;72:1520-1522.

3) Telag H, Alexi Meskishvilli V, Hetzer r ,Lange PE, Bergist F, Abdul Khalique H. Initial clinical menefestation and mid and longterm result after repair of DCRV in child and adult. Cardilol Young Jun 2008;18(3):268-274. 